\title{
5-ASA suppositories in hemorrhoidal disease
}

\author{
P Gionchetti, M Campieri, A BelluzZI, C Brignola, M Miglioli, L Barbara
}

P Gionchetti, M CAmpieri, A Belluzzi, C Brignola, M Miglioli, L BARBARA. 5-ASA suppositories in hemorrhoidal disease. Can J Gastroenterol 1992;6(1):18-20. Forty patients with active hemorrhoidal disease were entered into this double-blind trial, 20 of whom were randomized to treatment with 5-aminosalicylic acid (5-ASA) (500 mg) suppositories. Clinical and sigmoidoscopic assessment was carried out before the start of the trial and after two weeks of treatment. At the end of the study, 5-ASA suppositories showed results superior to those of placebo for all parameters evaluated $(\mathrm{P}<0.01)$. There were no adverse events reported related to the use of suppositories. 5-ASA suppositories are a valid therapeutic approach for hemorrhoidal disease as it reduces the intensity of all symptoms and significantly decreases congestion of the hemorrhoidal plexus.

Key Words: Hemorrhoidal disease, Mesalazine suppositories

\section{Les suppositoires de 5-ASA et les hémorroïdes}

RESUME: Quarante patients souffrant d'hémorroïdes actives ont participé à cet essai à double insu. On a prescrit des suppositoires de 5 - ASA $(500 \mathrm{mg})$ à 20 d'entre eux, choisis au hasard. L'examen clinique et sigmoïdoscopique a été effectué avant le traitement et deux semaines plus tard. Au terme de la présente étude, les suppositoires ont donné des résultats supérieurs au placebo pour tous les paramètres évalués $(\mathrm{P}<0,01)$, sans aucune réaction indésirable qui soit attribuable au traitement. Les suppositoires de 5-ASA constituent une forme de traitement valide des hémorroïdes. Ils réduisent l'intensité de tous les symptômes et soulagent la congestion du plexus hémorroïdal de façon significative.

Policlinico S Orsola - Istituto di Clinica Medica e Gastroenterologia - Via Massarenti,

9- 40100 Bologna, Italy.

Correspondence and reprints: Dr R Civardi, Smith Kline and French SpA, Direzione Medica, Viale Ortles, 12, 20139 Milano, Italy. Telephone 02-52572336

Received for publication October 1, 1991. Accepted November 6, 1991
$\mathrm{H}$ EMORRHOIDS ARE A FREQUENTLY occurring inflammatory process involving the hemorrhoidal plexus. They may occur in either sex and at any age, although a peak in prevalence is noted between the ages of 45 and 65 years with a subsequent decrease thereafter (1). Hemorrhoids are commonly considered to be a consequence of the ageing process, and the increase in frequency with age is believed to be caused by chronic constipation (2).

More recently, however, differences have come to light in the epidemiology of hemorrhoids and constipation, although this has not ruled out a causal relationship (1). This study also showed that 10 million people in the United States complained of hemorrhoids, corresponding to a prevalence rate of $4.4 \%$.

Hemorrhoidal irritation is frequently observed during endoscopic exam. ination and may occur together with other pathological findings, such as anal fissure and/or hyperemia, and mucosal friability. While hemorrhoids can be symptom free, it is the pain in the perianal region or, during defecation, the tenesmus and bleeding, that demand intervention. Treatment of this inflammatory process can be either 
via medical or surgical methods, and may also involve hygiene and dietary recommendations.

Pharmacological treatment of hemorrhoids is widely used, especially when inflammation, bleeding and pain are present. However, the efficacy of the various topical preparations which are commercially available is often disappointing. Several drug treatments containing corticosteroids, either alone or in combination with antibiotics or anesthetics, have been shown to be effective, but their prolonged use is limited because of the high incidence of side effects $(3,4)$.

5-aminosalicylic acid (5-ASA), the active moiety of sulphasalazine (5-7), has been shown to be highly effective in the treatment of mild or moderate attacks of ulcerative colitis when administered rectally, either as an enema $(8,9)$ or as a suppository $(10,11)$. A preliminary open study reported that 5-ASA (250 mg) suppositories administered twice daily for three weeks, were effective in reducing the severity of symptoms associated with hemorrhoids and produced endoscopically observed improvement (12).

The aim of the present study was to evaluate the efficacy of 5-ASA suppositories ( $500 \mathrm{mg}$ bid) versus placebo suppositories in the treatment of symptoms in patients with hemorrhoids.

\section{PATIENTS AND METHODS}

The study was designed as a doubleblind, randomized, placebo controlled trial of two weeks duration. Forty patients (21 males and 19 females) volunteered to take part in the study after receiving a full explanation of the nature and purpose of the trial. Patients with ulcerative proctitis, venereal disease, pregnancy or lactation, hypersensitivity to salicylate or clinically evident renal or hepatic impairment were excluded.

Patients were randomly allocated to receive one of the following regimens: one 5-ASA (500 mg) suppository bid for two weeks (Claversal; Smith Kline $\&$ French); one identical placebo suppository bid for two weeks.

Patients were not permitted any concurrent treatment for hemorrhoids,

TABLE 1

Clinical outcome of 40 patients before and after treatment with 5-ASA suppositories or placebo for hemorrhoidal disease

\begin{tabular}{lcccc}
\hline & & \multicolumn{2}{c}{ Number of patients } \\
Symptom & 5-ASA & \multicolumn{3}{c}{ Placebo } \\
\hline Pain & Before & After & Before & After \\
Bleeding & 20 & 6 & 20 & 13 \\
Mucus & 18 & 4 & 19 & 16 \\
Tenesmus & 10 & 3 & 9 & 6 \\
\hline
\end{tabular}

TABLE 2

Sigmoidoscopic outcome of 40 patients before and after treatment with 5-ASA suppositories or placebo for hemorrhoidal disease

\begin{tabular}{|c|c|c|c|c|}
\hline \multirow[b]{3}{*}{ Score } & \multicolumn{4}{|c|}{ Number of patients } \\
\hline & \multicolumn{2}{|c|}{ 5-ASA } & \multicolumn{2}{|c|}{ Placebo } \\
\hline & Before & After & Before & After \\
\hline 0 & 0 & 6 & 0 & 0 \\
\hline 1 & 1 & 6 & 2 & 7 \\
\hline 2 & 16 & 6 & 13 & 10 \\
\hline 3 & 3 & 2 & 5 & 3 \\
\hline Fissure & 6 & 6 & 8 & 8 \\
\hline Hyperemia & 8 & 2 & 5 & 5 \\
\hline
\end{tabular}

or any other medication administered rectally during the study.

Before the start of the trial, and after two weeks of treatment, patients were assessed both clinically and sigmoidoscopically. The endoscopic examination assessed the degree of hemorrhoidal congestion as 1,2 , or 3 , and determined whether or not anal fissure or mucosal hyperemia were present.

Small internal hemorrhoids which project a short way into the anal canal were rated 'degree 1'; if they prolapsed with defecation but reduced spontaneously they were rated 'degree 2'; 'degree 3 ' hemorrhoids had to be reduced manually; and 'degree 4' hemorrhoids were irreducible (13). The number of patients in each treatment group were compared by the $\chi^{2}$ rest for each assessment.

\section{RESULTS}

There were 20 patients in each group; 11 males and nine females in the 5-ASA group (mean age 41.3 years) and 10 males and 10 females in the placebo group (mean age 44.9 years). All patients showed clinical and endoscopic evidence of active hemorrhoid disease and complained of pain in the perianal region. In addition, some patients had bleeding, mucus in stools, tenesmus or pain during defecation in the perianal region. Fourteen patients (six in the 5-ASA group and eight in the placebo group) also presented with anal fissure, and 13 patients (eight in 5-ASA group and five in placebo group) had hyperemia at baseline. Clinical remission was considered to be the disappearance of all symptoms, and clinical improvement was considered to be the disappearance of at least one of the two principal symptoms (bleeding and pain).

After two weeks of treatment, 15 patients $(75 \%)$ in the 5-ASA group were in remission or had improved clinically, while eight patients $(40 \%)$ in the placebo group had an improvement of their symptoms (Table 1).

In particular, in the 5-ASA group, pain was reduced or absent in 14 of 20 patients $(70 \%)$, bleeding in 14 of 18 $(78 \%)$, mucus in seven of $10(70 \%)$ and tenesmus in 11 of $14(79 \%)$. In the placebo group, the percentage of patients showing improvement were $35,16,33$ and 33 for pain, bleeding, 
mucus and tenesmus, respectively. Statistical analysis showed the results to be significant $(\mathrm{P}<0.01)$ for all clinical parameters evaluated.

Endoscopically assessed remission was considered to be the endoscopic score of 0 and endoscopically assessed improvement was considered to be a reduction in degree of hemorrhoidal congestion of at least 1 .

Following the second endoscopic evaluation, 14 patients $(70 \%)$ had either improved or were in remission in the 5-ASA group, while only seven patients $(35 \%)$ had improved in the placebo group $(\mathrm{P}<0.01)$ (Table 2 ).

Fissures were still present in all 14 patients who presented these lesions

\section{REFERENCES}

1. Johanson JF, Sonnenberg A. The prevalence of hemorrhoids and chronic constipation. Gastroenterology 1990;98:380-6.

2. Haas PA, Fox TA, Haas GH. The pathogenesis of hemorrhoids. Dis Colon Rectum 1984;27:442-50.

3. Nishiki K, Kudoh D, Nishinga K, et al. Neriproct: Its antiinflammatory effect on an experimentally induced hemorrhoid model in the rat. Nippon Yak Zas 1988;92:227-40.

4. Smith RB, Moodie J. Comparative efficacy and tolerability of two ointment and suppository preparations (Uniroid and Proctosedyl) in the treatment of second degree hemorrhoids in general practice. Curr Med Res Opin 1988;11:34-40.

5. Azad Khan AK, Piris ], Truelove SC. An experiment to determine the active therapeutic moiety of sulphasalazine. Lancet 1977; ii:892-95.

6. Van Hees PAM, Bakker JH, Van Tongeren JHM. Effect of sulpha- initially. Mucosal hyperemia was reduced in six of the eight patients in the 5-ASA group, but no reduction was noted in patients treated with placebo.

\section{DISCUSSION}

This double-blind trial demonstrated the efficacy of 5-ASA suppositories in the treatment of symptoms of hemorrhoidal disease, confirming previous work (12). 5-ASA was significantly better than placebo for all parameters evaluated-both clinical and endoscopic.

In particular, 5-ASA reduced the intensity of all symptoms evaluated, probably via its anti-inflammatory activity, and decreased significantly the congestion of the hemorrhoidal plexus.

pyridine, 5-aminosalicylic acid and placebo suppositories in patients with idiopathic proctitis: A study to determine the active therapeutic moiety of sulphasalazine. Gut 1980;21:632-5.

7. Klotz U, Maier K, Fischer C, Heinkel $K$. Therapeutic efficacy of sulphasalazine and its metabolites in patients with ulcerative colitis and Crohn's disease. N Engl J Med 1980;303:1499-502.

8. Campieri M, Lanfranchi GA, Bazzocchi G, et al. Treatment of ulcerative colitis with high dose 5-aminosalicylic acid enemas. Lancet 1981;ii:270-1.

9. Sutherland LR, Martin F, Greer S, et al. 5-aminosalicylic acid enema in the treatment of distal ulcerative colitis, proctosigmoiditis and proctitis. Gastroenterology 1987;92:1894-8.

10. Campieri M, Gionchetti P, Belluzzi A, et al. 5-aminosalicylic acid suppositories in the management of ulcerative colitis. Dis Colon Rectum 1989;32:398-9.
Thus, the present data support the view that 5-ASA suppositories represent a valid therapeutic approach for hemorrhoidal disease, having the advantage of prolonged use free from significant side effects (14), compared with topical steroid preparations.

In the future it will be necessary to establish the optimum dose of 5-ASA suppositories and the most appropriate duration of treatment. Furthermore, it would be interesting to evaluate the efficacy of other 5-ASA rectal preparations, such as anal cream or gel. These are probably a more appropriate treatment for inflammation of the anal canal than are suppositories, which tend to spread up to the sigmoid region (15).

11. Campieri M, Gionchetti P, Belluzzi A, et al. Topical treatment with 5-aminosalicylic acid in distal ulcerative colitis by using a new suppository preparation. A doubleblind placebo controlled trial. Int J Colorect Dis 1990;5:79-81.

12. Neiger A. Therapie schmerzhaftentsundlicher Hamorrhoidalkomplikationen mit mesalazin. Therapiewoche 1987;37:519-22.

13. Goligher JC. Surgery of the Anus, Rectum and Colon, 3 rd edn. Springfield: Charles C Thomas, 1975.

14. Sutherland LR, Martin F. 5 -aminosalicylic acid enemas in the maintenance of remission in distal ulcerative colitis and proctitis. Can J Gastroenterol 1987;1:3-6.

15. Williams CN, Haber G, Aquino JA. Double-blind, placebo-controlled evaluation of 5-ASA suppositories in active distal proctitis and measurement of extent of spread using $99 \mathrm{mTc}$ labeled 5-ASA suppositories. Dig Dis Sci 1987;32:71s-5s. 


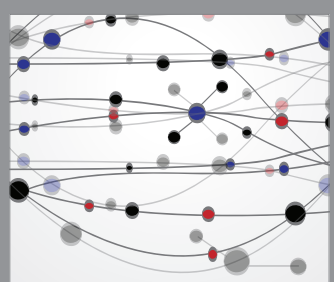

The Scientific World Journal
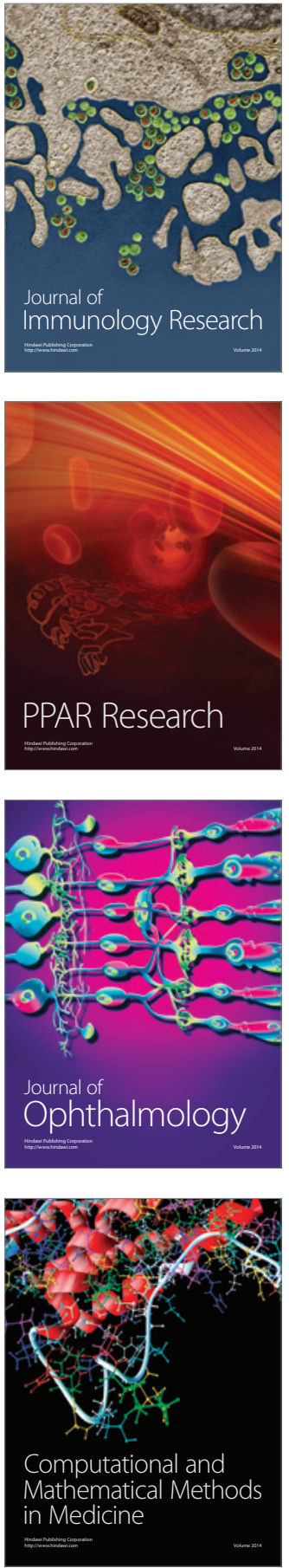

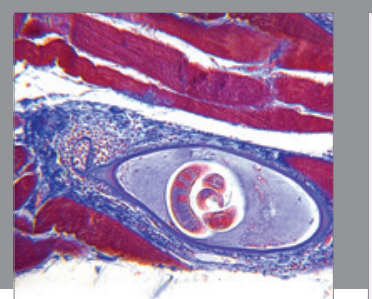

Gastroenterology Research and Practice

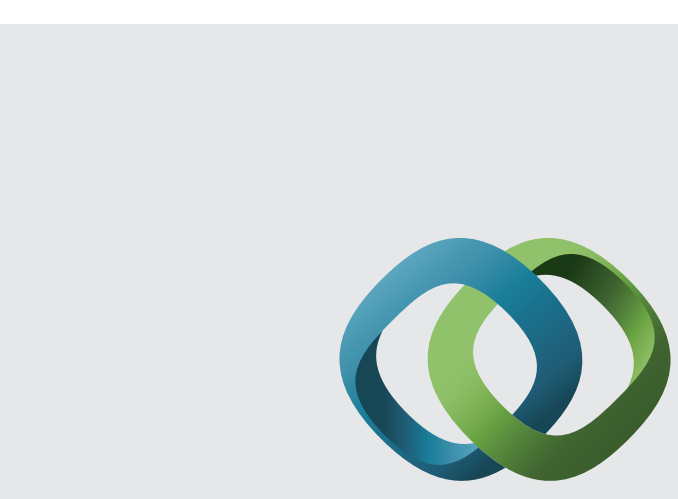

\section{Hindawi}

Submit your manuscripts at

http://www.hindawi.com
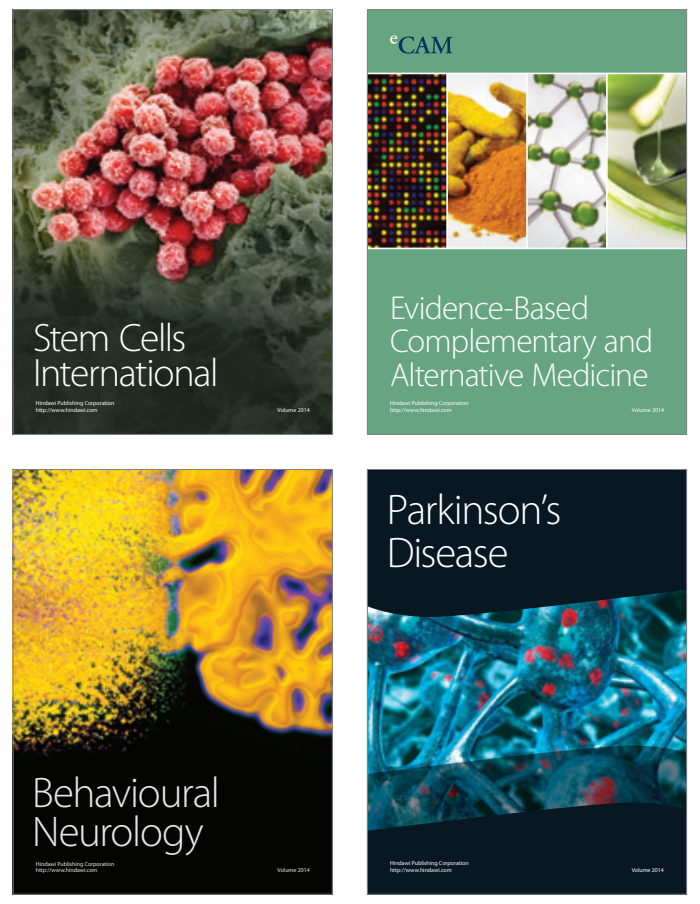
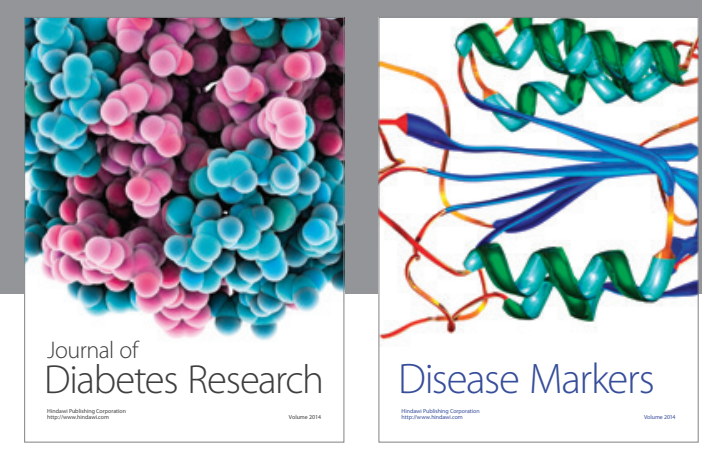

Disease Markers
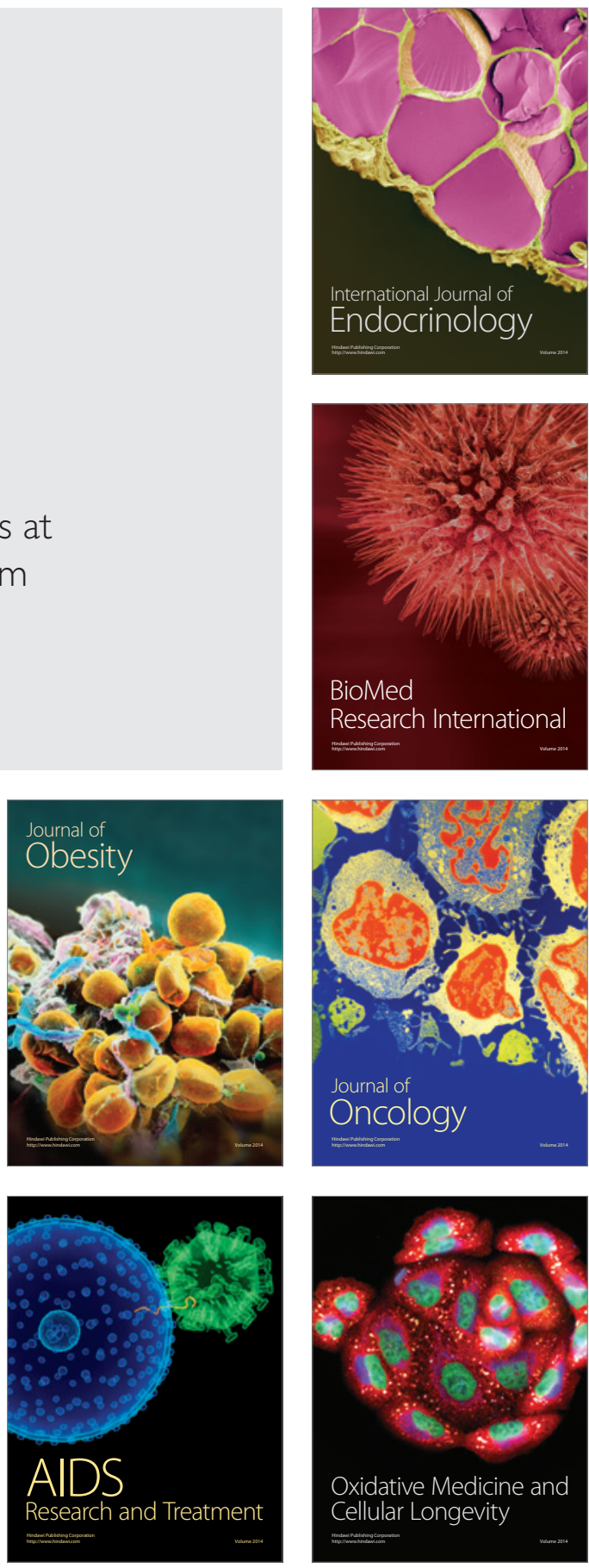